\title{
Epidemiological Study of Small Ruminant Gastrointestinal Helminthosis in Borana Lowlands, Southern Oromia, Ethiopia
}

\author{
Dereje Teshome $^{1,}$, , Tamirat Tessema ${ }^{1}$, Sisay Kumsa ${ }^{1}$, Misgana Naramo ${ }^{2}$ \\ ${ }^{1}$ Oromia Agricultural Research Institute, Yabello Pastoral and Dryland Agriculture Research Center, Yabello, Ethiopia \\ ${ }^{2}$ Hadiya Zone Livestock and Fisheries Resource Office, Shone, Ethiopia
}

Email address:

derejeteshe@gmail.com (D. Teshome)

${ }^{*}$ Corresponding author

\section{To cite this article:}

Dereje Teshome, Tamirat Tessema, Sisay Kumsa, Misgana Naramo. Epidemiological Study of Small Ruminant Gastrointestinal Helminthosis in Borana Lowlands, Southern Oromia, Ethiopia. International Journal of Biomedical Engineering and Clinical Science.

Vol. 7, No. 3, 2021, pp. 43-47. doi: 10.11648/j.ijbecs.20210703.11

Received: May 14, 2021; Accepted: August 16, 2021; Published: August 23, 2021

\begin{abstract}
Epidemiological survey of gastrointestinal (GI) helminthes parasites in small ruminant in four districts (Arero, Moyale, Teltele and Yabello) of Borana lowland, Southern Oromia, was conducted during the period of October 2016 to June 2017 to estimate the prevalence, to identify the species of parasite involved and to access the risk factors of GI helminthes parasites in small ruminant. For this study a total of 939 faecal samples (655 sheep and 284 goats) were collected directly from the rectum and examined based parasitological procedures. In this study an overall prevalence of helminthosis was 597 (63.6\%) in small ruminants whereas $423(64.6 \%)$ in sheep and $174(61.3 \%)$ in goats harbor one or more GI helminthes parasites. Strongyles were the most prevalent parasites observed. The prevalence is higher in Moyale (70.8\%), followed by $66 \%, 60.5 \%$, and $47.1 \%$ in Yabello, Arero and Teltele respectively. The occurrence of helminthosis in the four districts was found statistically significant $(\mathrm{P}<0.05)$. Significant $(\mathrm{P}<0.05)$ association was observed among age and body condition of the study animals. Even though the prevalence of helminthosis in sheep $64.6 \%$ was higher than prevalence in goat $61.3 \%$ statistically it was found insignificant $(\mathrm{P}>0.05)$. Breed and Sex was also not significantly $(\mathrm{P}>0.05)$ associated with the occurrence of small ruminant helminthosis. The study indicates that helminthes parasites are the major constraints that affect productivity of small ruminant. Awareness creation to the pastoralists in the study area about the effect of small ruminant helminthosis and designing appropriate control methods has a paramount importance to improve the productivity of small ruminant.
\end{abstract}

Keywords: Helminthes, Prevalence, Small Ruminant, Borana, Ethiopia

\section{Introduction}

Parasitic infections pose a serious health threat and remain one of the major impediments to small ruminant production in many part of the world including Ethiopia [1]. Parasitic infections pose a serious health threat and limit the productivity of livestock due to the associated morbidity and mortality [2]. More specifically, plethora of parasitic diseases plays a detrimental role in hampering small ruminant production leading to serious economic loss [3]. Moreover, parasite helminthes also cause susceptibility to other disease $[4,5]$.

The problem is much more severe in tropical countries due to very favorable environmental condition for parasite transmission, poor nutrition of host animals, and poor sanitation in facilities where animals are housed. As a result diseases caused by helminthes remain one of the major impediments to small ruminant production in tropics [6].

In Ethiopia helminthosis is responsible for $25 \%$ mortality and $3.8 \%$ weight loss in highland sheep and cause an estimated annual loss of about 700 million Ethiopian birr [7]. Helminthosis of sheep and goat is among the endoparasite infections that are responsible for economic losses through reduced productivity and increased mortality [8]. The loss through reduced productivity is related to reduction of food 
intake, stunted growth, reduced work capacity, cost of treatment and control of helminthosis [9, 10]. The effect of infestation by gastrointestinal helminths varies according to the parasite concerned, the degree of infestation and other risk factors such as species, age, season and intensity of worm burden [11].

Although considerable work has been done on endoparasites of sheep and goats in many parts of Ethiopia [12-16], no report so far has been published on the prevalence of small ruminant GI helminthosis in the study areas. Therefore, this study was conducted to determine the prevalence of GI helminthes parasite and associated risk factors in the study area.

\section{Material and Methods}

\subsection{Study Area}

The study was conducted from October 2016 to June 2017 in four districts (Arero, Moyale, Teltele and Yabello) of Borana zone, southern Ethiopia, which is located about 565 $\mathrm{km}$ to South East of Addis Ababa. Yabello town which is the city of administrative bodies of Borana zone has approximately more than 35,000 human populations. Resource use in the Borana rangeland is largely communal though with crop cultivation and private enclosures that appear to be increasing in recent decades. The area receives bimodal pattern of rainfall, with the long rains falling between March and May and the short rains between September and November. Spatial and temporal variability in both the quantity and distribution of rainfall renders the area semi-arid, with an average annual rainfall ranging from $400 \mathrm{~mm}$ in the South to $600 \mathrm{~mm}$ in the North. The average temperature varies from $13.1^{\circ} \mathrm{C}$ to $25.2^{\circ} \mathrm{C}$ per annual [17].

\subsection{Study Population}

In this study a total of 939 small ruminant, (655 sheep and 284 goats) of different age groups, both sex and two breeds (local and cross); cross breeds are breeds of Dorper with black head Somali sheep and Boer goat with Borana goat cross were included in the study. Animal in the study were sheep and goats kept under traditional extensive management system and some of them from semi intensive; those are from Yabello Pastoral and Dryland Agriculture Research Center (YPDARC) sheep and goat farm.

\subsection{Study Design and Sample Size Determination}

The total sample size was determined based on internationally set standard formula [18]. There was no previously published documented prevalence in the study area. Therefore, sample size was calculated using 95\% confidence level at 5\% absolute precision and expected prevalence of $50 \%$ by substituting the value, the minimum sample sizes of 384 small ruminants were considered for this study. But in order to increase the precision 939 small ruminants were sampled.

\subsection{Study Methodology}

Fecal sample were collected from 939 small ruminants (655 sheep and 284 goats) per rectum using gloved fingers. The collected fecal sample were placed in universal sampling bottles and labeled. The age, body condition, breed, districts, sex and species were recorded. Finally samples were transported to Yabello regional veterinary laboratory for parasitological examination. Then collected samples stored at $4^{\circ} \mathrm{C}$ for qualitative and quantitative examination in the laboratory. Sedimentation and floatation techniques were employed to concentrate the helminthes egg in faces and examined microscopically for presence of egg following standard procedures $[19,20]$. Helminth eggs were identified based on their color, shape and contents as described by [21].

\subsection{Statistical Analysis}

The data collected was checked, coded and entered in to Microsoft excel. SPSS version 17.0 statistical program was employed for data analysis. The prevalence of helminthosis was determined by dividing the number of positive samples by the total number of animals examined and expressed as Percentages $(\%)$. Chi-square $\left(\mathrm{x}^{2}\right)$ to measure association between prevalence of the parasite, species of animal, breed, age, sex, body condition and districts were the statistical tools applied. In all analyses confidence level was held at $95 \%$ and a P-value less than 0.05 were taken as significant.

\section{Result}

\subsection{Prevalence of Small Ruminant GIT Parasite by Risk Factors}

The overall prevalence form a total 939 small ruminant fecal samples examined, $63.6 \%(n=597)$ were found to harbor one or more GI helminthes parasites. The prevalence of gastrointestinal helminthes parasite was $64.6 \%$ in sheep and $61.3 \%$ in goat (Table 1). The prevalence of infection according to host species was compared and from a total 655 sheep examined 423 were found infected and of 284 goats 174 were found infected by one or more gastrointestinal helminthes parasite. Even though the prevalence of helminthosis in sheep $(64.6 \%)$ observed was higher compared to goat $(61.3 \%)$, the difference among species group were statistically insignificant $(\mathrm{P}>0.05)$.

The effect of sex on the helminthosis prevalence was assessed and relatively high prevalence was recorded in male (64.6\%) than that of females $(62.9 \%)$ animals. However, the difference between sex groups was not statistically significant $(p>0.05)$.

The breed of animals was assumed as one of risk factor for the prevalence of parasite. The results of the study were $67.4 \%$ and $63.2 \%$ in cross and local breed respectively; But no significant difference was observed in gastrointestinal helminthes between cross and local breed $(\mathrm{P}>0.05)$.

Body conditions of sampled animals were considered as one risk factor and the higher prevalence of helminthosis was observed in poor $(81.8 \%)$, followed by medium (63.8) and 
good $(55.2 \%)$ body condition of the animal. The prevalence shows there was a highly statistical significant difference between body condition score $(\mathrm{P}<0.05)$.

The prevalence recorded among age basis includes $60.0 \%$ in adult and $72.4 \%$ in young of age categories were infected by one or more parasite species. The age specific prevalence among age categories was statistically significant $(\mathrm{P}=<0.05)$

The prevalence of infection according to the districts was $60.5 \%, 70.8 \%, 47.1 \%$ and $66.0 \%$ in Arero, Moyale, Teltele and Yabello respectively. The result indicate that there is significant difference in prevalence statistically $(\mathrm{P}<0.05)$ summarized in (Table 1).

Table 1. Prevalence of small ruminant gastrointestinal helminthes parasite by risk factors.

\begin{tabular}{|c|c|c|c|c|c|c|}
\hline \multicolumn{2}{|c|}{ Risk factors } & $\begin{array}{l}\text { № } \\
\text { Examined }\end{array}$ & $\begin{array}{l}\text { № } \\
\text { positive }\end{array}$ & $\begin{array}{l}\text { Prevalence } \\
{[\%]}\end{array}$ & $\mathbf{X}^{2}$ & $\begin{array}{l}\text { P- } \\
\text { value }\end{array}$ \\
\hline \multirow{4}{*}{ Species } & Sheep & 655 & 423 & 64.6 & 0.939 & 0.333 \\
\hline & Goat & 284 & 174 & 61.3 & & \\
\hline & Total & 939 & 597 & 63.6 & & \\
\hline & Female & 555 & 349 & 62.9 & 0.283 & 0.594 \\
\hline \multirow[t]{3}{*}{ Sex } & Male & 384 & 248 & 64.6 & & \\
\hline & Total & 939 & 597 & 63.6 & & \\
\hline & Adult & 667 & 400 & 60.0 & 12.946 & 0.000 \\
\hline \multirow[t]{3}{*}{ Age } & Young & 272 & 197 & 72.4 & & \\
\hline & Total & 939 & 597 & 63.6 & & \\
\hline & Cross & 86 & 58 & 67.4 & 0.610 & 0.435 \\
\hline \multirow[t]{2}{*}{ Breed } & Local & 853 & 539 & 63.2 & & \\
\hline & Total & 939 & 597 & 63.6 & & \\
\hline \multirow{3}{*}{$\begin{array}{l}\text { Body } \\
\text { Condition }\end{array}$} & Good & 326 & 180 & 55.2 & 30.406 & 0.000 \\
\hline & Medium & 470 & 300 & 63.8 & & \\
\hline & Poor & 143 & 117 & 81.8 & & \\
\hline \multirow{6}{*}{ Districts } & Total & 939 & 597 & 63.6 & & \\
\hline & Arero & 167 & 101 & 60.5 & 17.114 & 0.001 \\
\hline & Moyale & 130 & 92 & 70.8 & & \\
\hline & Teltele & 104 & 49 & 47.1 & & \\
\hline & Yabello & 538 & 355 & 66.0 & & \\
\hline & Total & 939 & 597 & 63.6 & & \\
\hline
\end{tabular}

\subsection{Prevalence of Small Ruminant GIT Parasite}

Strongyles, paramphistomum, Eimeria species, Moniezia, Ascaris, and Trichuris were the parasite identified as a single and mixed infection (Figure 1).

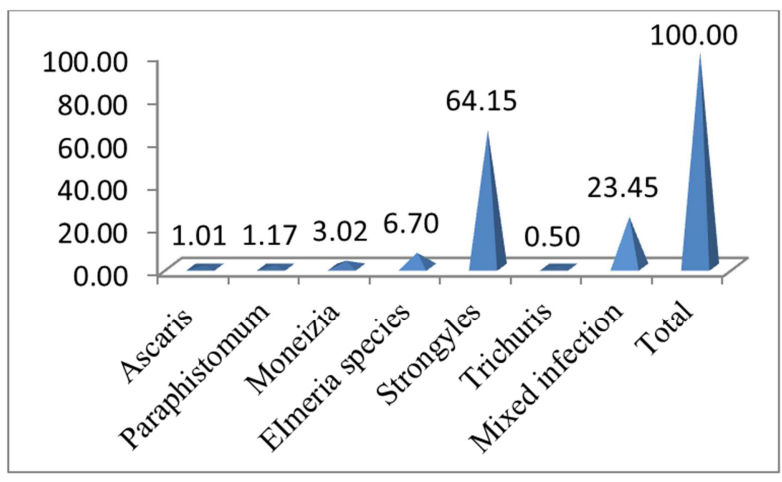

Figure 1. Prevalence of gastrointestinal helminthes parasite.

\section{Discussion}

The present finding revealed that the occurrence of overall prevalence rate of helminthosis was $63.6 \%$. The result showed that $64.6 \%$ and $61.3 \%$ of sheep and goat respectively were infested with one or more parasite species. This finding is lower than [13, 14, 22-26] and [7, 27] in different parts of Ethiopia. The decreased in the GIT parasite in this study as compared to other studies in the country could be due to different management system [14].

Higher prevalence of GIT parasites was observed in sheep than in the goats which is in agreement with other works in Ethiopia [3] and elsewhere in the world [28, 29] and this is assumed to be due to the grazing habit of the sheep where they graze closer to the ground this makes exposure to parasites than goats.

Age was showed significant influence on the prevalence of helminthosis, which could be related to the higher susceptibility of younger animals. This report is agreement with reports in Ethiopia [14, 16], and elsewhere [30-33, 5]. Age was considered as an important risk factor in GIT helminthosis [34]. Several authors have documented that adult and old animals develop acquired immunity [35, 36] against helminth infections as they get mature due to repeated exposure [16]

Based on sex of the animal higher prevalence of GIT parasite was revealed in male than female animals which is in agreement with previous reported [37, 34]. In contrast, [16] reported higher prevalence of GIT parasitic infection in female.

In the present study coprological examination showed the distribution of different classes helminth included nematodes followed by cestode and Eimeria species in both host animals The prevalence of nematode was significantly higher than that of cestode and coccidian in both host species. Among the nematodes; stronglyes were the most abundant species of GIT parasite in both sheep and goat of study area. The reports were agrees with previous finding by $[6,33]$. This finding contrast with the reports of [38-40, 5, 34, 15] all of which reported the abundance of haemonchus specie in sheep and goat. This variation might be due to difference in agro ecology, climate and production system.

The infection rate of GIT parasite was statistically analyzed on the basis of body condition to study the impact of the parasite in emaciating infected animals. The result of the study indicated that infection rates in poor body condition sheep and goat was significantly higher $(\mathrm{p}<0.05)$ than that of medium and good body condition animals. Similar results which support the present finding were reported by [41, 42].

The study indicated that districts of the study area show significant with the prevalence of GIT helminthes parasite. The presence of association between districts and prevalence of the parasite were due to different in climate, agro ecology production and management system of the district. This result reveals that there is no significant difference $(\mathrm{P}>0.05)$ in prevalence of GIT helminthes parasite between local and cross breed in the study area. The likely explanation may be that local and cross breed in the study area graze in the same grazing lands so that the chance of acquiring the disease or becoming of infected is therefore similar. 


\section{Conclusion and Recommendations}

The high prevalence of gastrointestinal helminthes parasites indicates that gastrointestinal helminthosis to be important health problem in the study area. Strongyle parasites were the most predominant and Trichuris were the least gastro intestinal parasites of small ruminant observed in the current finding. The majority of study animals were infected by two or more parasite species. The study indicated that age, body condition and districts were the most significant risk factors for the occurrence of gastro intestinal parasite. Therefore, based on the conclusion the following recommendation forwarded:

1) To reduce the risk of reinfection and pasture contamination strategic anthelmintic treatment should be implemented

2) Further studies with large area coverage are needed to establish the seasonal epidemiology of these parasites.

3) Well-designed an integrated control program for economically significance GIT helminthes parasite should implemented

\section{Funding Information}

This study was supported by the Oromia Agricultural Research Institute (IQQO).

\section{Compliance with Ethical Standards}

Not applicable.

\section{Conflict of Interest}

The authors declare that they have no competing interests.

\section{Acknowledgments}

The authors are grateful to the pastoralists from our study area for their participation and cooperation in this study.

\section{References}

[1] Golo, D., Tadelle, S., Wubishet Z, Kula, J., Gete, G., and Nejash, A. (2017). Prevalence of small ruminant gastrointestinal parasites infections and associated risk factors in selected districts of Bale zone, south eastern Ethiopia. Journal of Parasitology and Vector Biology. 9: 81-88.

[2] Tibbo M, Aragaw K, Philipsson J, Malmfors B, Nasholm A, Ayalew W, Rege J (2006). Economics of sub-clinical helminthosis control through anthelmintics and nutrition in indigenous Menz and Awassi-Menz crossbred sheep in Ethiopia. Unpublished

[3] Teklye B (1991). Epidemiology of endoparasites of small ruminants in sub-saharan Africa. Proceedings of Fourth National Livestock Improvement Conference. Addis Ababa, Ethiopia, pp. 13-15. November 7-11.
[4] Kumba, F. F., Katjivena. H., kauta. G. and Lutaaya. E., (2003). Seasonal evolution of faecal egg output by gastrointestinal worms, in goat on communal farms in eastern Namibia onderstepoort J. vet Res, 70; 265-271.

[5] Githigia, S. Thamsborg. M. Maingi. N. and Munyua W. (2005) The epidemiology of gastrointestinal nematodes in goat in the low potential area of Thika district, Kenya. Bull. Anim. Health prod. Afi., 53; 5-12.

[6] Maichomo, M. W., J. M. Kagira and Walker. T., (2004). The point prevalence of gastrointestinal parasite in calves, sheep and goat in Magadi division, south-western Keny. Onderstepoort J. vet. Res., 71; 257-261.

[7] Haileleul N (2002). Study on prevalence of GIT helminthes of small ruminants in and around Wolayta Soddo, southern Ethiopia. DVM Thesis, Faculty of veterinary medicine, Addis Ababa university, Debre-Zeit. Ethiopia, p. 353.

[8] Perry B. D., Randolph T. F., McDermott J. J., Sones K. R., Thornton P. K. (2002). Investing in animal health research to alleviate poverty. International Livestock Research Institute (ILRI), Nairobi, Kenya, p. 148.

[9] Pedreira J, Silva A. P., Andrade R. S., Suarez J. L., Arias M., Lomba C., Diaz. P., Lopez. C., Banos P. D., Morrondo P (2006). Prevalence of gastrointestinal parasites in sheep and parasite control practices in North-West Spain. Prev. Vet. Med., 75: $56-62$.

[10] Odoi A, Gathuma JM, Gachuiri CK, Omore A (2007). Risk factors of gastrointestinal nematode parasite infections in small ruminants kept in smallholder mixed farms in Kenya. BMC Vet. Res., 3 (6): 1186-1746.

[11] ILCA (International Livestock Center for Africa) (1990). Annual report. 1989. Addis Ababa, Ethiopia.

[12] Jobre Y, Ali M (2000). Dry season bovine fasciolosis in northwestern part of Ethiopia. Revue Med. Vet., 151 (6): 493-500.

[13] Abebe W, Esayasu G (2001). Survey on ovine and caprine gastro-intestinal helminthosis in eastern part of Ethiopia during the dry season of the year. Revue Vet. Med., 152 (5): 379-384.

[14] Regassa F, Teshale S, Reta D, Yosef K (2006). Epidemiology of gastrointestinal parasites of ruminants in Western Oromia, Ethiopia. Int. J. Appl. Res. Vet. Med., 4 (1): 51-57

[15] Kumsa B, Tolera A, Nurfeta A (2010). Comparative efficacy of seven brands of albendazole against naturally acquired gastrointestinal nematodesin sheep in Hawassa, Southern etghiopia, Turk. J. Vet. Anim. Sci., 34:417-425.

[16] Dagnachew S, Amamute A, Temegen W (2011). Epidemiology of gastrointestinal helminthosis of small ruminants in selected sites of North Gondar zone, Northwest Ethiopia. Ethiop. Vet. J., 15 (2): 57-68

[17] Coppock, D. L. (1994). The Borana plaute of southern Ethiopia. Synthesis of pastoral research, Development and change, 1986-91. System study. International Livestock Center for Africa (ILCA), Addis Ababa, Ethiopia. No.4.

[18] Thrusfield, M., (2005). Veterinary Epidemiology. 3rd ed. UK: Black well science ltd. p. 233

[19] Hansen J, Perry B (1994). The Epidemiology, Diagnosis and Control of Helminthes parasites of Ruminants. 2nd edition. Nairobi, Kenya; ILRADHenderix, 1998. 
[20] Hendrix CM (1998) Diagnostic veterinary parasitology (2nd edn), Mosby Inc, USA, 136: 108-116.

[21] Soulsby, E. J. (1982). Helminths, Arthropods and Protozoa of Domesticated Animals. 7th ed. London: Bailliere Tindall. p. 119-127.

[22] Sissay, M. M., Uggla, A. and Waller, P. J. (2007). Epidemiology and seasonal dynamics of gastrointestinal nematode infections of sheep in a semi-arid region of eastern Ethiopia. Veterinary Pasasitology. 143: 311-321.

[23] Tefera M, Batu G, Bitew M. Prevalence of Gastrointestinal Parasites of Sheep and Goats In and Around Bedelle, SouthWestern Ethiopia. 2011, The Internet Journal of Veterinary Medicine, 8: 3-5.

[24] Kumsa B, Tadesse T, Sori T, Dugum R, Hussen B (2011) Helminths of sheep and goats in Central Oromia (Ethiopia) during the dry season. J Anim Vet Adv 10(14):1845-1849.

[25] Genene R. (1994). A study of prevalence of ovine GIT helminthes in and around kombolcha.. DVM thesis, Faculty of Veterinary Medicine.

[26] Tesfaye H (1998) Ovine and bovine helminthosis in Kelela, South Wollo. In: Proceedings of EVA conference, Addis Ababa, Ethiopia, p: 30.

[27] Amenu, A. (2005): Epidemiology of gastrointestinal tract nematodiosis of small ruminant in three different agroecological zones of southern Ethiopia. MSc, Thesis FVM, AAU, Debre Zeit, Ethiopia.

[28] Waruiru, R. M., M. N. Mutume and R. O. Otieno, (2005). gastrointestinal parasitic infecton of Machakos district, Kenya. Bull, Anim. Health. prod. Afi, 53; 25-43.

[29] Asif M, Azeem S, Asif S, Nazir S (2008). Prevalence of Gastrointestinal Parasites of Sheep and Goats in and around Rawalpindi and Islamabad, Pakistan. J. Vet. Anim. Sci., 1: 1417.

[30] Fritsch T, Kaufmann J. Ptister K. (1993). Parasite spectrum and seasonal epidemiology of gastrointestinal nematodes of small ruminants in Gambia. Veterinary Parasitology, 49 (2-4): 271-283.

[31] Keyyu J. D., Kassuku A. A., Kyvsgaard N C., Willingham A. L. (2003). Gastrointestinal nematodes in indigenous zebu cattle under pastoral and nomadic management systems in the lower plain of Southern highlands of Tanzania. 2003, Vet Res Communication. 27 (5): 371-380.
[32] Melkamu T (1991). Prevalence of gastrointestinal helminthes of small ruminants in four Awrajas of Eastern Shoa Administrative Regions. DVM thesis, Faculty of Veterinary Medicine, Addis Ababa, University, Debre-Zeit, Ethiopia.

[33] Ng'anga CJ, Maingi N, Munyua WK, Kanyari PW (2004). Epidemiology of gastrointestinal helminths infection in Dorper sheep in semi-arid area of Kenya. Ondestepool J. Vet. Res., 71 (3): 219-226.

[34] Raza, M. A. Z. Iqbal, A. Jabbar and M. Yaseen (2007). Point prevalence of gastrointestinal helminthosis in ruminants in southern Punjab, Pakistan. J. Helminthol., 81: 323-328.

[35] Urquhart GM, Aremour J, Dunchan JL, Dunn AM, Jeninis FW (1996). Veterinary Parasitology 2nd edition. The University of Glasgow, Blackwell Sciences, Scotland, pp. 3-13.

[36] Tasawar Z, Ahmad S, Lashari MH and Hayat CS (2010) Prevalence of Haemonchus contortus in sheep at Research Centre for Conservation of Sahiwal Cattle (RCCSC) Jehangirabad, District Khanewal, Punjab, Pakistan. Pak J Zool 42:735-739.

[37] Gualy M, Schackert M, Hoffmann B, Erhardt G (2006). Influence of sex on the resistance of sheep lambs to an experimental Haemonchus contortus infection. Dtsch. Tierarztl. Wochenschr, 113: 178-181.

[38] Agyei, A. D., 2003. Epidemiological studies on the gastrointestinal parasitic infection of lambs in the Coastal Savanna regions of Ghana. Tropical Animal Health and Production, 35: 207-217.

[39] Garcia, J. A., J. G. Rodriguez-Diego, G. Torres-Hernandez, M. Mahieu，E. G. Garcia，R. Gonzalez-Garduno, 2007). The epizootiology of ovine gastrointestinal strongyle small ruminants Res., 72; 119-126.

[40] Bersissa, K. and Ajebu. N., (2008). Comparative efficacy of albendazole, tetramisole and ivermectin against gastrointestinal nematode in naturally infected sheep in Hawassa, southern Ethiopia. Rev. Med. vet, 159; 593-598.

[41] Graber, M (1975) Helminths and helminthosis of domestic and wild animals of Ethiopia. Bulletin of Anim. Hlth. And prod. In Africa 23; 57-86.

[42] Radosititiss, D. M; blood, D. C. and Gray, C. C. (1994) veterinary medicine. A text book of the disease of cattle, sheep, goat, pigs and horses. $8^{\text {th }}$ Edt. ELBS and Bailleiire Tindall. 